(2) Open Access Full Text Article

\title{
Pharmacokinetics and pharmacodynamics of
} linezolid in plasma/cerebrospinal fluid in patients with cerebral hemorrhage after lateral ventricular drainage by Monte Carlo simulation

This article was published in the following Dove Press journal:

Drug Design, Development and Therapy

\section{Xiaofei $\mathrm{Wu}^{\prime}$ \\ Yan Tang' \\ Xiaohua Zhang' \\ Chenchen $\mathrm{Wu}^{2}$ \\ Lingti Kong ${ }^{3}$}

'Department of Emergency Internal Medicine, the First Affiliated Hospital of Bengbu Medical College, Bengbu 233004, People's Republic of China; ${ }^{2}$ Department of Endocrinology, the First Affiliated Hospital of Bengbu Medical College, Bengbu 233004, People's Republic of China; ${ }^{3}$ Department of Pharmacy, the First Affiliated Hospital of Bengbu Medical College, Bengbu 233004, People's Republic of China
Correspondence: Lingti Kong Department of Pharmacy, the First Affiliated Hospital of Bengbu Medical College, Bengbu 233004, People's Republic of China Email konglingti@I63.com
Objective: We investigated the pharmacokinetic (PK) and pharmacodynamic (PD) parameters of linezolid in patients who had suffered cerebral hemorrhage after lateral ventricular drainage. Materials and methods: Ten patients with cerebral hemorrhage after lateral ventricular drainage with stroke-associated pneumonia who were given linezolid were enrolled. Plasma and cerebrospinal fluid (CSF) samples were taken at appropriate intervals after the first administration of linezolid and assayed by high-performance liquid chromatography (HPLC). Then, PK parameters were estimated, and a Monte Carlo simulation was used to calculate the probability of target attainments (PTAs) for linezolid achieving the PK/PD index at different minimal inhibitory concentrations (MICs).

Results: The maximum concentration of linezolid in plasma and CSF was reached at $1.00 \mathrm{~h}$ and $3.10 \mathrm{~h}$, respectively. The average penetration of linezolid in CSF was 56.81\%. If the area under the plasma concentration vs time curve from zero to the final sampling time $\left(\mathrm{AUC}_{0-24 \mathrm{~h}}\right) /$ MIC $\geq 59.1$ was applied as a parameter, the PTA of linezolid in plasma could provide good coverage (PTA $\geq 90 \%$ ) only for pathogens with a MIC of $\leq 2 \mu \mathrm{g} / \mathrm{mL}$, whereas it could be achieved in CSF with a MIC of $\leq 1 \mu \mathrm{g} / \mathrm{mL}$. If $\% \mathrm{~T}>\mathrm{MIC} \geq 40 \%$ was applied as a parameter, the PTA of linezolid in plasma/CSF could provide good coverage if the MIC was $\leq 4 \mu \mathrm{g} / \mathrm{mL}$.

Conclusions: For patients with infection of the central nervous system and who are sensitive to the drug, the usual dosing regimens of linezolid can achieve a good therapeutic effect. However, for critically ill or drug-resistant patients, an increase in dose, the frequency of administration, or longer infusion may be needed to improve the curative effect.

Keywords: linezolid, cerebral hemorrhage, plasma, cerebrospinal fluid, pharmacokinetics, pharmacodynamics, Monte Carlo simulation

\section{Introduction}

Ventricular drainage is used to relieve cerebral edema and lower intracranial pressure in various neurologic disorders, but some complications remain: postoperative re-bleeding in the brain, intracranial infection, bleeding in the upper gastrointestinal tract, central fever, hyperglycemia, and renal insufficiency. ${ }^{1}$ Intracranial infection can develop into a very serious nosocomial infection that prolongs hospitalization, increases the patient's medical expenses, and can even cause death directly. Studies have shown that in complications caused by brain surgery, the prevalence of intracranial infection is 1.8 to $8.9 \%$ and that of mortality is 3.8 to $30 \% .^{2}$ 
Gram-positive cocci are the most common causative pathogenic bacteria of intracranial infection after craniotomy. ${ }^{3}$ The proportion of methicillin-resistant coagulase-negative staphylococci and methicillin-resistant Staphylococcus aureus has been increasing gradually. For patients with intracranial infection, vancomycin treatment, as recommended by the Infectious Diseases Society of America, is often used, but its penetration into cerebrospinal fluid (CSF) is only 0 to $18 \%$. In addition, vancomycin is often accompanied by adverse reactions and bacterial resistance., ${ }^{4,5}$ As a result, intracranial infection is difficult to control, and a mortality prevalence of $20 \%$ to $40 \%$ has been reported. ${ }^{6}$ Improvement of the treatment of intracranial infection has become an urgent problem.

Linezolid is an oxazolidinone, and was approved for marketing by the US Food and Drug Administration in $2000 .^{7}$ Linezolid can inhibit the synthesis of bacterial proteins by acting on the $50 \mathrm{~S}$ ribosomal subunit of bacteria, and only at the initiation stage of translation. ${ }^{8-11}$ Because of its special mechanisms, it has become a better alternative to vancomycin. ${ }^{12-15}$ The clinical indications of linezolid are: nosocomial pneumonia, septicemia caused by vancomycinresistant enterococci, complicated infections of skin and soft tissue, and community-acquired pneumonia with bacteremia. However, the indications for treatment of intracranial infection after craniocerebral procedures have not been stated. ${ }^{16}$

Due to various pathophysiologic factors (eg, edema, fluid infusion, change in hepatic/renal function), significant individual differences exist in the distribution and elimination of drugs in patients who have undergone cranial surgery but suffered cerebral hemorrhage complicated by central nervous system (CNS) infection.

We wished to evaluate the effect of pathophysiologic changes on linezolid pharmacokinetics (PK) and provide evidence for linezolid use in the treatment of CNS infection in this specific patient population.

\section{Materials and methods}

\section{Chemicals and reagents}

Linezolid standard (purity of $99.58 \%$ in powder form) was purchased from MedChem Express (Monmouth Junction, NJ, USA). Chloramphenicol standard (purity of $99.8 \%$ in powder form) was obtained from the National Institutes for Food and Drug Control (Beijing, People's Republic of China). Linezolid for injection $\left(Z y v o x{ }^{\circledR}\right.$, Fresenius Kabi Norge AS, Halden, Norway) was purchased from Fresenius Kabi Norge AS (Oslo, Norway). Acetonitrile of high-performance liquid chromatography (HPLC) grade was obtained from Thermo Fisher
Scientific (Waltham, MA, USA). Milli- ${ }^{\mathrm{TM}}$ water (EMD Millipore, Billerica, MA, USA) was used for all samples.

\section{Study participants}

The study protocol was in compliance with the Helsinki Declaration and approved by the ethics committee of the First Affiliated Hospital of Bengbu Medical College (Bengbu, People's Republic of China), and written informed consents had been signed by patients or their families.

The study was conducted in the emergency internal medicine department of the First Affiliated Hospital of Bengbu Medical College (the largest tertiary care center in northern Anhui). From May 2016 to December 2017, 10 patients with severe cerebral hemorrhage were enrolled into our study. Inclusion criteria were: age $>18$ years and stroke-associated pneumonia with no further cerebral bleeding.

\section{Study design and sample collection}

Linezolid injection (Zyvox) was administered as a 1-h infusion of $0.6 \mathrm{~g}$ every $12 \mathrm{~h}$ and infused with a micro-pump at a steady rate. Blood samples $(1 \mathrm{~mL})$ were collected using direct-draw vacuum blood-collection tubes containing heparin immediately before the first infusion as well as 0.5 , 1.0, 2.0, 3.0, 4.0, 6.0, 8.0 and $12.0 \mathrm{~h}$ after infusion. After blood samples had been centrifuged $(3,000 \mathrm{rpm}, 5 \mathrm{~min}$, room temperature), $0.2 \mathrm{~mL}$ of the separated plasma samples were stored at $-20^{\circ} \mathrm{C}$ until assay. CSF samples $(1 \mathrm{~mL})$ were collected, processed and stored in the same manner as the blood samples.

\section{Sample preparation}

After the addition of $20 \mu \mathrm{L}$ of internal standard (chloramphenicol, $1 \mathrm{mg} / \mathrm{mL}$ ) and $0.4 \mathrm{~mL}$ of acetonitrile to plasma or CSF $(0.2 \mathrm{~mL})$ in a $1.5-\mathrm{mL}$ Eppendorf tube, samples were mixed and centrifuged at $14,000 \mathrm{rpm}$ for $5 \mathrm{~min}$ at room

Table I Baseline characteristics of the study cohort

\begin{tabular}{lllllll}
\hline $\begin{array}{l}\text { Patient Sex } \\
\text { no }\end{array}$ & $\begin{array}{l}\text { Age } \\
\text { (years) }\end{array}$ & $\begin{array}{l}\text { Weight } \\
(\mathbf{k g})\end{array}$ & $\begin{array}{l}\text { Albumin } \\
(\mathbf{g} / \mathbf{L})\end{array}$ & $\begin{array}{l}\text { Creatinine } \\
\text { clearance } \\
\text { (mL/min) }\end{array}$ & $\begin{array}{l}\text { Dose } \\
(\mathbf{m g} / \mathbf{k g})\end{array}$ \\
\hline $\mathrm{I}$ & Male & 67 & 63 & 43.6 & 119 & 9.52 \\
2 & Male & 53 & 70 & 48.0 & 112 & 8.57 \\
3 & Female & 66 & 58 & 46.9 & 106 & 10.34 \\
4 & Female & 59 & 62 & 34.2 & 124 & 9.68 \\
5 & Male & 68 & 96 & 41.5 & 112 & 6.25 \\
6 & Male & 60 & 62 & 48.9 & 102 & 9.68 \\
7 & Male & 51 & 55 & 49.0 & 108 & 10.91 \\
8 & Male & 65 & 67 & 33.9 & 113 & 8.96 \\
9 & Female & 64 & 58 & 50.6 & 117 & 10.34 \\
10 & Male & 55 & 61 & 44.8 & 107 & 9.84 \\
\hline
\end{tabular}




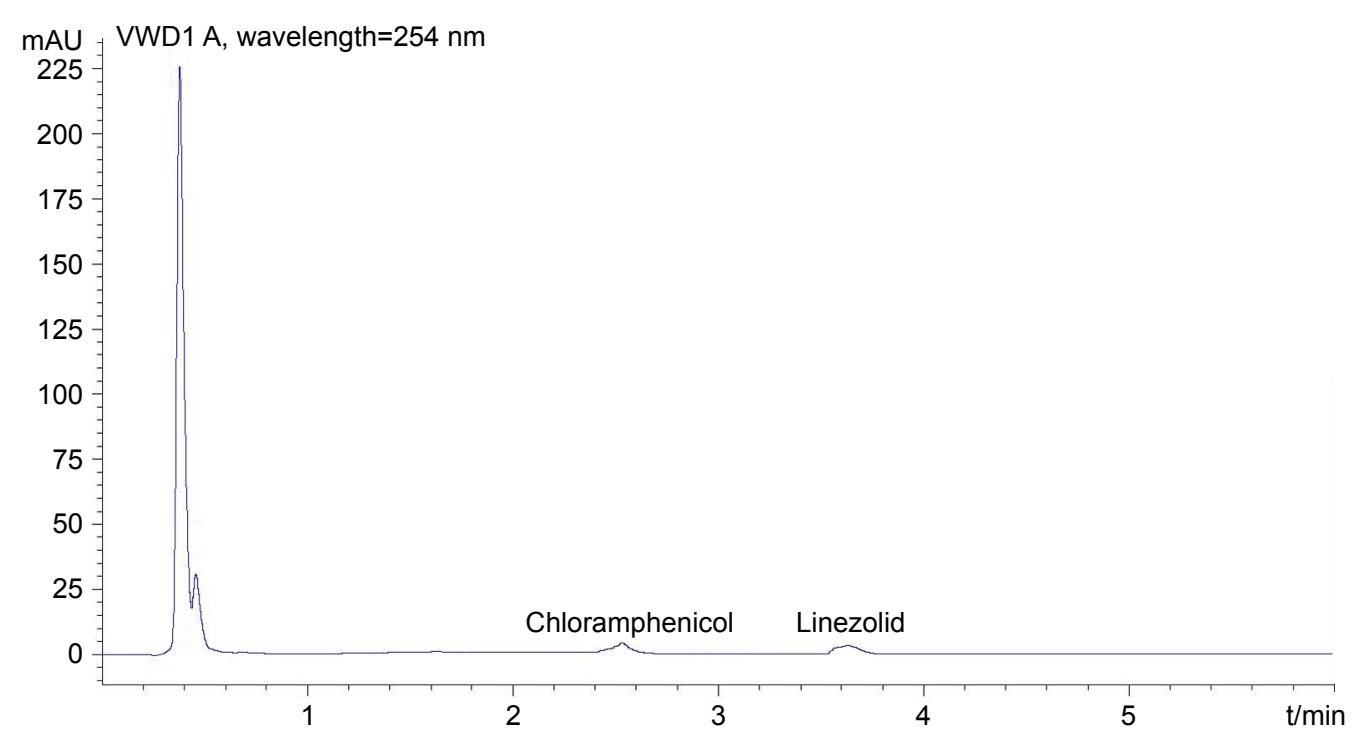

Figure I HPLC chromatogram of linezolid from CSF at $3 \mathrm{~h}$ after the infusion. Abbreviations: HPLC, high-performance liquid chromatography; CSF, cerebrospinal fluid.

temperature. Then, $10 \mu \mathrm{L}$ of the organic layer was injected into the HPLC system for analyses.

\section{Linezolid assay}

When the method for determining concentrations of linezolid was established, we used an HPLC-MS/MS (positive mode, multiple reaction monitoring, 338.2 $\rightarrow 296.2$ ) and HPLC to measure linezolid in the plasma/CSF, respectively. The results of the two methods were consistent, indicating that there was no interference with metabolites at this retention time. Therefore, we used the HPLC method for its simplicity and economy.

Briefly, the linezolid in the organic layer was placed in a HPLC system (1290; Agilent Technologies, Santa Clara, CA, USA) equipped with a quaternary pump, autosampler, thermostat column, and ultraviolet detector. Samples were

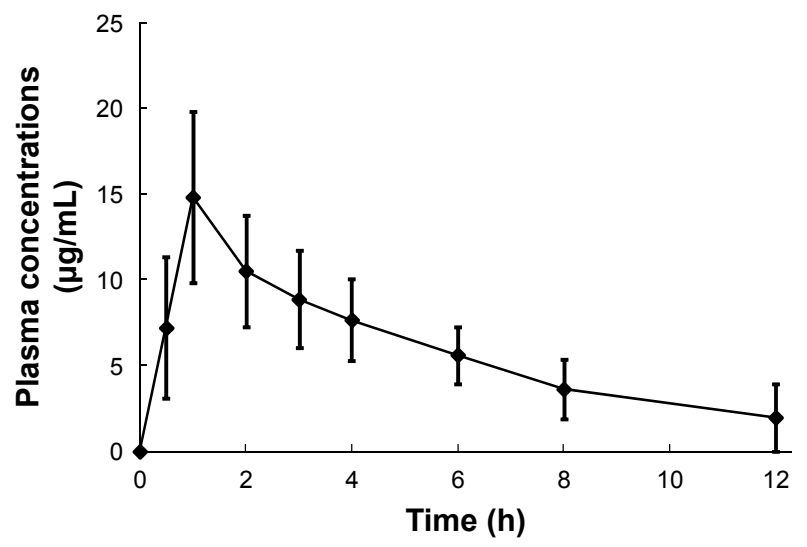

Figure 2 Plasma concentration-time curves of linezolid in patients. Each point represents the mean $\pm \mathrm{SD}(\mathrm{N}=10)$. separated on a Hypersil BDS (Elite, Dalian, People's Republic of China) $\mathrm{C}_{18}$ column $(2.1 \times 100 \mathrm{~mm}, 3.5 \mu \mathrm{M})$ at $30^{\circ} \mathrm{C}$. The mobile phase was water-methanol $(80: 20, \mathrm{v} / \mathrm{v})$ at a flow rate of $0.8 \mathrm{~mL} / \mathrm{min}$ with a detection wavelength of $254 \mathrm{~nm}$.

\section{PK}

According to the drug concentration vs time profile of each patient, PK parameters [peak time $\left(\mathrm{T}_{\max }\right)$, peak concentration $\left(\mathrm{C}_{\max }\right)$, elimination half-life $\left(\mathrm{T}_{1 / 2}\right)$, area under the curve $\left(\mathrm{AUC}_{0-\mathrm{t}}\right)$, apparent volume of distribution $(\mathrm{Vd})$ and total clearance (CL)] were calculated using WinNonlin 6.1 (Certara, Princeton, NJ, USA), and a non-compartmental model was employed.

\section{PK/pharmacodynamics (PD) simulations}

Linezolid is an antimicrobial agent with a long duration and time-dependent activity. Hence, the value of the area under the curve/minimum inhibitory concentration (AUC/ $\mathrm{MIC}$ ) and the time that the plasma concentration is the MIC $(\% \mathrm{~T}>\mathrm{MIC})$ are used as indices of PD evaluation. ${ }^{17}$ Based on the work of Cai et al, we selected $\mathrm{AUC}_{0-\mathrm{t}} / \mathrm{MIC} \geq 59.1$ and $\% \mathrm{~T}>\mathrm{MIC} \geq 40 \%$ as target values for effective therapy. ${ }^{18}$ A Monte Carlo simulation was employed to calculate the probability of target attainments (PTAs) based on different MIC values from a PK/PD perspective, and Crystal Ball (Oracle, Redwood City, CA, USA) was used. ${ }^{19}$

\section{Results}

\section{Patient demographics}

Patient demographics (sex, age, weight, albumin levels, creatinine concentrations) are shown Table 1. 
Table 2 Pharmacokinetic parameters of linezolid in plasma

\begin{tabular}{|c|c|c|c|c|c|c|}
\hline $\begin{array}{l}\text { Patient } \\
\text { no }\end{array}$ & $\begin{array}{l}T_{1 / 2} \\
\text { (h) }\end{array}$ & $\begin{array}{l}T_{\max } \\
\text { (h) }\end{array}$ & $\begin{array}{l}C_{\max } \\
(\mu \mathrm{g} / \mathrm{mL})\end{array}$ & $\begin{array}{l}\text { AUC } \\
(h \cdot \mu g / m L)\end{array}$ & $\begin{array}{l}C L \\
(L / h)\end{array}$ & $\begin{array}{l}\text { Vd } \\
(\mathrm{L} / \mathrm{kg})\end{array}$ \\
\hline 1 & 5.77 & 1 & 16.50 & 126.00 & 4.76 & 39.64 \\
\hline 2 & 7.29 & I & 7.44 & 65.15 & 9.21 & 96.80 \\
\hline 3 & 3.52 & I & 26.61 & 125.52 & 4.78 & 24.27 \\
\hline 4 & 2.39 & I & 14.97 & 50.87 & 11.79 & 40.59 \\
\hline 5 & 3.49 & I & 11.72 & 64.08 & 9.36 & 47.17 \\
\hline 6 & 3.30 & I & 14.46 & 65.30 & 9.19 & 43.68 \\
\hline 7 & 4.13 & I & 16.52 & 65.34 & 9.18 & 54.72 \\
\hline 8 & 3.30 & I & 14.07 & 65.44 & 9.17 & 43.66 \\
\hline 9 & 5.78 & I & 14.25 & 99.21 & 6.05 & 50.47 \\
\hline 10 & 3.60 & I & 11.48 & 66.99 & 8.96 & 46.55 \\
\hline Mean \pm SD & $4.26 \pm 1.52$ & $1.00 \pm 0.00$ & $14.80 \pm 4.95$ & $79.39 \pm 29.26$ & $8.25 \pm 2.28$ & $48.75 \pm 18.73$ \\
\hline
\end{tabular}

Abbreviations: $T_{1 / 2}$, elimination half-life $T_{\max }$, peak time; $C_{\max }$, peak concentration; $A U C$, area under the curve; $C L$, total clearance; $V d$, apparent volume of distribution.

\section{Linezolid concentrations and PK parameters}

Samples of plasma and CSF were analyzed at different time points and PK parameters calculated. Figure 1 shows the HPLC chromatogram of linezolid from CSF $3 \mathrm{~h}$ after linezolid administration.

The profile of plasma concentration vs time of linezolid is shown in Figure 2. The plasma PK parameters of linezolid are shown in Table 2. The maximal plasma concentration $\left(\mathrm{C}_{\max }\right)$ was $14.80 \pm 4.95 \mu \mathrm{g} / \mathrm{mL}$. The area under the plasma concentration vs time curve from zero to the final sampling time $\left(\mathrm{AUC}_{0-24 \mathrm{~h}}\right)$ was $79.39 \pm 29.26 \mathrm{~h} \cdot \mu \mathrm{g} / \mathrm{mL}$.

The profile of CSF concentration vs time of linezolid is shown in Figure 3. The CSF PK parameters of linezolid are shown in Table 3. The peak concentration in CSF $(8.46 \pm 1.99 \mu \mathrm{g} / \mathrm{mL})$ was reached $3.10 \pm 0.32 \mathrm{~h}$ after intravenous infusion, and $\mathrm{AUC}_{0-24 \mathrm{~h}}$ was $45.10 \pm 8.78 \mathrm{~h} \cdot \mu \mathrm{g} / \mathrm{mL}$. The mean penetration of linezolid in the CSF was $56.81 \%$.

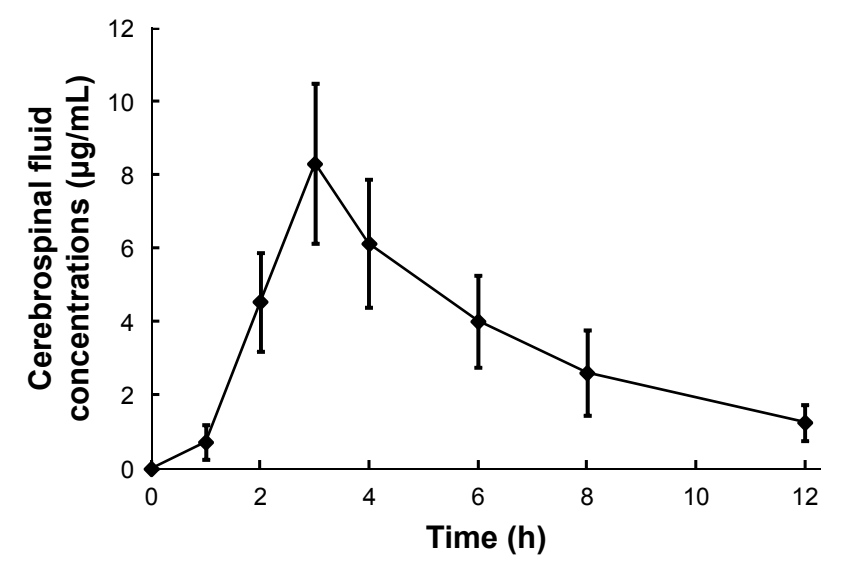

Figure 3 Cerebrospinal-fluid concentration-time curves of linezolid in patients. Note: Each point represents the mean \pm SD $(n=10)$.

\section{Attainment of PK/PD targets}

PTAs of linezolid in plasma and CSF at different MIC values are shown in Table 4.

When $\mathrm{AUC}_{0-24 \mathrm{~h}} / \mathrm{MIC} \geq 59.1$ was applied as a parameter, the PTA of linezolid in plasma was $99.21,74.51,9.94$ and $0.05 \%$ when the MIC was $1,2,4$ and $8 \mu \mathrm{g} / \mathrm{mL}$; the PTA in CSF was $98.22,6.00,0.00$ and $0.00 \%$, respectively.

When $\% \mathrm{~T}>\mathrm{MIC} \geq 40 \%$ was applied as a parameter, the PTA of linezolid in plasma was 99.81, 97.41, 75.88 and $21.16 \%$ when the MIC was $1,2,4$ and $8 \mu \mathrm{g} / \mathrm{mL}$; the PTA in CSF was $99.54,90.56,49.10$ and $8.13 \%$, respectively.

\section{Discussion}

Linezolid is first-line treatment for multiple drug-resistant Staphylococcus aureus and vancomycin-resistant bacterial infection. Linezolid plays an important part in the treatment of critically ill patients with severe infection..$^{20-22}$

Existing PK parameters have been based mainly on healthy volunteers. Only a minority of PK parameters in special disease states have been reported. ${ }^{23-25} \mathrm{PK}$ parameters have not been reported in the CSF of patients who have suffered cerebral hemorrhage after surgical drainage. We analyzed linezolid in this specific patient population to see if the linezolid concentration could achieve an effective therapeutic range while limiting its toxicity and delaying the development of drug resistance. Our study also provides valuable information for monitoring of the stability of linezolid in blood/CSF in this specific patient population who had ventricular drainage without further bleeding. As shown in Tables 2 and 3 , the $\mathrm{T}_{1 / 2}$ of linezolid in plasma was only $4.3 \mathrm{~h}$, whereas the $T_{1 / 2}$ was $5.3 \mathrm{~h}$ in CSF. The main cause of a higher $T_{1 / 2}$ in CSF than in plasma was drug slow diffusion across the bloodbrain barrier, which was similar to previous research. ${ }^{26-28}$ 
Table 3 Pharmacokinetic parameters of linezolid in cerebrospinal fluid

\begin{tabular}{|c|c|c|c|c|c|c|}
\hline $\begin{array}{l}\text { Patient } \\
\text { no }\end{array}$ & $\begin{array}{l}T_{1 / 2} \\
\text { (h) }\end{array}$ & $\begin{array}{l}T_{\max } \\
\text { (h) }\end{array}$ & $\begin{array}{l}C_{\max } \\
(\mu \mathrm{g} / \mathrm{mL})\end{array}$ & $\begin{array}{l}\text { AUC } \\
(h \cdot \mu g / m L)\end{array}$ & $\begin{array}{l}\text { CL } \\
(L / h)\end{array}$ & $\begin{array}{l}\text { Vd } \\
\text { (L/kg) }\end{array}$ \\
\hline 1 & 6.13 & 3 & $|2.3|$ & 65.12 & 4.61 & 40.78 \\
\hline 2 & 5.38 & 4 & 7.17 & 41.23 & 8.73 & 67.73 \\
\hline 3 & 4.75 & 3 & 5.09 & 35.39 & 9.66 & 66.22 \\
\hline 4 & 3.26 & 3 & 7.14 & 52.48 & 5.60 & 26.37 \\
\hline 5 & 4.82 & 3 & 7.27 & 47.62 & 7.43 & 51.75 \\
\hline 6 & 5.10 & 3 & 9.85 & 36.25 & 12.37 & 162.46 \\
\hline 7 & 6.77 & 3 & 9.09 & 45.40 & 10.63 & 103.88 \\
\hline 8 & 4.25 & 3 & 9.90 & 42.67 & 8.68 & 165.92 \\
\hline 9 & 7.08 & 3 & 8.71 & 45.95 & 10.72 & 109.51 \\
\hline 10 & 5.51 & 3 & 8.10 & 38.90 & 13.03 & 103.68 \\
\hline Mean \pm SD & $5.31 \pm 1.15$ & $3.10 \pm 0.32$ & $8.46 \pm 1.99$ & $45.10 \pm 8.78$ & $9.15 \pm 2.73$ & $89.83 \pm 48.04$ \\
\hline
\end{tabular}

Abbreviations: $T_{1 / 2}$, elimination half-life; $T_{\max }$, peak time; $C_{\max }$, peak concentration; $A U C$, area under the curve; $C L$, total clearance; $V d$, apparent volume of distribution.

Linezolid has a long duration of antimicrobial activity which is dependent upon time. The $\mathrm{AUC}_{0-24 \mathrm{~h}} / \mathrm{MIC}$ and $\% \mathrm{~T}>$ $\mathrm{MIC}$ are used commonly as indices of PD evaluation. Studies have shown the $\mathrm{AUC}_{0-24 \mathrm{~h}} / \mathrm{MIC} \geq 59.1$ and $\% \mathrm{~T}>\mathrm{MIC} \geq$ $40 \%$ can be used as target values of a good curative effect. In the present study, because we have difficulty in obtaining MIC data from pathogens in cerebral hemorrhage patients or some other comparable population in our hospital, the typical MICs $(1,2,4$ and $8 \mu \mathrm{g} / \mathrm{mL})$ were chosen according to the similar literatures and EUCAST guidance. ${ }^{29,30}$ Also, the PTAs were estimated using a Monte Carlo simulation for linezolid to achieve its $\mathrm{PK} / \mathrm{PD}$ index. ${ }^{31}$

We found that when $\mathrm{AUC}_{0-24 \mathrm{~h}} / \mathrm{MIC} \geq 59.1$ was applied as a parameter, the PTA of linezolid in plasma could provide good coverage (PTA $\geq 90 \%$ ) only for pathogens with a MIC of $\leq 2 \mu \mathrm{g} / \mathrm{mL}$, whereas it could be achieved in CSF with a MIC of $\leq 1 \mu \mathrm{g} / \mathrm{mL}$. When $\%$ TMIC $\geq 40 \%$ was applied as a parameter, the PTA of linezolid in plasma/CSF could provide good coverage if the MIC was $\leq 4 \mu \mathrm{g} / \mathrm{mL}$. These results suggest that the standard dose and administration of linezolid can achieve a good therapeutic effect in patients

Table 4 PTAs of linezolid in plasma and cerebrospinal fluid for different MIC values

\begin{tabular}{|c|c|c|c|c|}
\hline \multirow{3}{*}{$\begin{array}{l}\text { MIC } \\
(\mu g / m L)\end{array}$} & \multicolumn{4}{|l|}{ PTA (\%) } \\
\hline & \multicolumn{2}{|l|}{ Plasma } & \multicolumn{2}{|c|}{ Cerebrospinal fluid } \\
\hline & AUC $_{0-24 h} / M I C$ & $\% \mathbf{T}>\mathbf{M I C}$ & AUC $_{0-24 h} / M I C$ & $\% \mathbf{T}>\mathbf{M I C}$ \\
\hline 1 & 99.49 & 99.81 & 98.22 & 99.54 \\
\hline 2 & 74.51 & 97.41 & 6.62 & 90.56 \\
\hline 4 & 9.94 & 75.88 & 0.00 & 49.10 \\
\hline 8 & 0.05 & 21.16 & 0.00 & 8.13 \\
\hline
\end{tabular}

who are sensitive to the drug based on a drug-sensitivity test. In critically ill patients or drug-resistant patients, the dose, frequency of administration or duration of intravenous infusion may have to be increased to improve the therapeutic effect.

We found that it was more likely to achieve $\% \mathrm{~T}>$ $\mathrm{MIC} \geq 40$ than $\mathrm{AUC}_{0-24 \mathrm{~h}} / \mathrm{MIC} \geq 59.1$ considering that: (i) we were caring for critically ill patients with cerebral hemorrhage complicated by intracranial infection; and (ii) the average penetration of linezolid in CSF was only $56.81 \%$. We propose stricter use of $\mathrm{AUC}_{0-24} \mathrm{~h} / \mathrm{MIC} \geq 59.1$ for dosing and administration to help increase the drug concentration in CSF. In addition, monitoring of the concentration will help to adjust the drug dose to achieve the best therapeutic effect and, ultimately, to promote the rational use of drugs.

\section{Acknowledgment}

This study was supported financially by the Research Innovation Program for College Graduates of Bengbu Medical College (Byycx 1653).

\section{Disclosure}

The authors report no conflicts of interest in this work.

\section{References}

1. Murthy SB, Moradiya Y, Shah J, Hanley DF, Ziai WC. Incidence, predictors, and outcomes of ventriculostomy-associated infections in spontaneous intracerebral hemorrhage. Neurocrit Care. 2016;24:389-396.

2. Yang ZJ, Zhong HL, Wang ZM, Zhao F, Liu PN. Prevention of postoperative intracranial infection in patients with cerebrospinal fluid rhinorrhea. Chin Med J (Engl). 2011;124:4189-4192.

3. Arabi Y, Memish ZA, Balkhy HH, Francis C, Ferayan A, Al Shimemeri A, et al. Ventriculostomy-associated infections: incidence and risk factors. Am J Infect Cont. 2005;33:137-143.

4. Marinho DS, Huf G, Ferreira BL, et al. The study of vancomycin use and its adverse reactions associated to patients of a Brazilian university hospital. BMC Res Notes. 2011;4:236. 
5. An SY, Hwang EK, Kim JH, et al. Vancomycin-associated spontaneous cutaneous adverse drug reactions. Allergy Asthma Immunol Res. 2011;3:194-198.

6. Kessler AT, Kourtis AP. Treatment of meningitis caused by methicillinresistant Staphylococcus aureus with linezolid. Infection. 2007;35: 271-274.

7. Pappas G, Ierodiakonou V, Falagas ME. Lost in translation: differences in antimicrobial indication approval policies between the United States and Europe. Clin Ther. 2009;31:1595-1603.

8. Fortún J, Martín-Dávila P, Navas E, et al. Linezolid for the treatment of multidrug-resistant tuberculosis. J Antimicrob Chemother. 2005; $56: 180-185$.

9. Ippolito JA, Kanyo ZF, Wang D, et al. Crystal structure of the oxazolidinone antibiotic linezolid bound to the $50 \mathrm{~S}$ ribosomal subunit. J Med Chem. 2008;51:3353-3356.

10. De Vriese AS, Coster RV, Smet J, et al. Linezolid-induced inhibition of mitochondrial protein synthesis. Clin Infect Dis. 2006;42:1111-1117.

11. Kloss P, Xiong L, Shinabarger DL, Mankin AS. Resistance mutations in $23 \mathrm{~S}$ rRNA identify the site of action of the protein synthesis inhibitor linezolid in the ribosomal peptidyl transferase center. $J \mathrm{Mol}$ Biol. 1999;294:93-101.

12. Caffrey AR, Morrill HJ, Puzniak LA, Laplante KL. Comparative effectiveness of linezolid and vancomycin among a national veterans affairs cohort with methicillin-resistant Staphylococcus aureus pneumonia. Pharmacotherapy. 2014;34:473-480.

13. Fu JJ, Ye XH, Chen C, Chen S. The efficacy and safety of linezolid and glycopeptides in the treatment of Staphylococcus aureus infections. PLoS One. 2013;8:e58240.

14. Vardakas KZ, Kioumis I, Falagas ME. Association of pharmacokinetic and pharmacodynamic aspects of linezolid with infection outcome. Curr Drug Metab. 2009;10:2-12.

15. Falagas ME, Vardakas KZ. Benefit-risk assessment of linezolid for serious Gram-positive bacterial infections. Drug Saf. 2008;31:753-768.

16. Barrett JF. Linezolid Pharmacia Corp. Curr Opin Investig Drugs. 2000; 1:181-187.

17. Andes D, van Ogtrop ML, Peng J, Craig WA. In vivo pharmacodynamics of a new oxazolidinone (linezolid). Antimicrob Agents Chemother. 2002;46:3484-3489.

18. Cai Y, Bai N, Liu X, Liang B, Wang J, Wang R. Pharmacokinetic/ pharmacodynamic research on three different infusion time regimens of linezolid in healthy Chinese volunteers. Int J Clin Pharmacol Ther. 2015;53:765-771.

19. Rayner CR, Forrest A, Meagher AK, Birmingham MC, Schentag JJ. Clinical pharmacodynamics of linezolid in seriously ill patients treated in a compassionate use programme. Clin Pharmacokinet. 2003;42: $1411-1423$
20. Wasserman S, Meintjes G, Maartens G. Linezolid in the treatment of drug-resistant tuberculosis: the challenge of its narrow therapeutic index. Expert Rev Anti Infect Ther. 2016;14:901-915.

21. Takada H, Hifumi T, Nishimoto N, et al. Linezolid versus vancomycin for nosocomial pneumonia due to methicillin-resistant Staphylococcus aureus in the elderly: a retrospective cohort analysis: Effectiveness of linezolid in the elderly. Am J Emerg Med. 2017;35:245-248.

22. Ament PW, Jamshed N, Horne JP. Linezolid: its role in the treatment of gram-positive, drug-resistant bacterial infections. Am Fam Physician. 2002;65:663-670.

23. Dong H, Xie J, Wang T, et al. Pharmacokinetic/pharmacodynamic evaluation of linezolid for the treatment of staphylococcal infections in critically ill patients. Int J Antimicrob Agents. 2016;48:259-264.

24. Cojutti P, Maximova N, Crichiutti G, Isola M, Pea F. Pharmacokinetic/ pharmacodynamic evaluation of linezolid in hospitalized paediatric patients: a step toward dose optimization by means of therapeutic drug monitoring and Monte Carlo simulation. J Antimicrob Chemother. 2015; 70:198-206.

25. Luque S, Grau S, Alvarez-Lerma F, et al. Plasma and cerebrospinal fluid concentrations of linezolid in neurosurgical critically ill patients with proven or suspected central nervous system infections. Int J Antimicrob Agents. 2014;44:409-415.

26. Zhao Y, Cudkowicz ME, Shefner JM, et al. Systemic pharmacokinetics and cerebrospinal fluid uptake of intravenous ceftriaxone in patients with amyotrophic lateral sclerosis. J Clin Pharmacol. 2014;54: 1180-1187.

27. Cole DE, Lester-McCully CM, Widemann BC, Warren KE. Plasma and cerebrospinal fluid pharmacokinetics of the Akt inhibitor, perifosine, in a non-human primate model. Cancer Chemother Pharmacol. 2015; 75:923-928.

28. Li J, He S, Yang Z, Lu C. Pharmacokinetics and cerebrospinal fluid penetration of norvancomycin in Chinese adult patients. Int J Antimicrob Agents. 2017;49:603-608.

29. Chung EK, Fleming MR, Cheatham SC, Kays MB. Population pharmacokinetics and pharmacodynamics of doripenem in obese, hospitalized patients. Ann Pharmacother. 2017;51:209-218.

30. Jaruratanasirikul S, Thengyai S, Wongpoowarak W, et al. Population pharmacokinetics and Monte Carlo dosing simulations of meropenem during the early phase of severe sepsis and septic shock in critically ill patients in intensive care units. Antimicrob Agents Chemother. 2015;59: 2995-3001.

31. Kong L, Tang Y, Zhang X, et al. Pharmacokinetic/pharmacodynamic analysis of meropenem for the treatment of nosocomial pneumonia in intracerebral hemorrhage patients by Monte Carlo simulation. Ann Pharmacother. 2017;51:970-975.
Drug Design, Development and Therapy

\section{Publish your work in this journal}

Drug Design, Development and Therapy is an international, peerreviewed open-access journal that spans the spectrum of drug design and development through to clinical applications. Clinical outcomes, patient safety, and programs for the development and effective, safe, and sustained use of medicines are the features of the journal, which
Dovepress

has also been accepted for indexing on PubMed Central. The manuscript management system is completely online and includes a very quick and fair peer-review system, which is all easy to use. Visit http://www.dovepress.com/testimonials.php to read real quotes from published authors. 